EDUCAÇ̃̃̃O

V.10 • N.2 • Número Temático - 2020

ISSN Digital: 2316-3828

ISSN Impresso: 2316-333X

DOI: 10.17564/2316-3828.2020v10n2p50-65

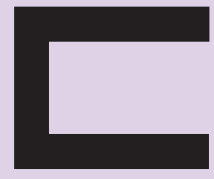

五 $N \mathrm{~N}$ 开 立同(

CIENTÍFICAS

\title{
A ESCRITA DE FÃS NO CONTEXTO TRANSMIDIÁTICO: IMPLICAÇÕES DAS FANFICS NO PROCESSO DE APRENDIZAGEM'
}

FAN WRITING IN THE TRANSMIDIATIC CONTEXT: IMPLICATIONS OF FANFICS IN THE LEARNING PROCESS

\section{ESCRITURA DEL FANS EN EL CONTEXTO TRANSMIIIÁTICO: IMPLICACIONES DE LAS FICCIONES DEFANS EN EL PROCESO DE APRENDIZAJE}

Daniella de Jesus Lima Luís Paulo Leopoldo Mercado 3

1 Estudo e pesquisa desenvolvidos com o apoio da Coordenação de Aperfeiçoamento de Pessoal de Nível Superior (CAPES) - Brasil.

\section{RESUMO}

0 estudo investiga as possibilidades de aprendizagem por meio da autoria na produção de fanfics. A pesquisa tem como objetivo investigar como os sujeitos imersos na cultura digital, por meio da autoria em rede, do ponto de vista da transmidiação marcada nas fanfics, aprendem a partir das produções e colaborações. A metodologia contempla a abordagem qualitativa, a pesquisa bibliográfica e netnográfica. Os dados foram coletados a partir dos registros feitos por meio da observação participante e da análise dos questionários aplicados aos participantes da pesquisa, beta readers do site Spirit Fanfics e Histórias. Com isso, foi elucidado que por meio da liberdade, da autoria e coautoria em rede e da colaboração os sujeitos engajam-se na produção de narrativas ficcionais. E, uma vez que precisam apropriar-se de conteúdo específico, tratado nas histórias, quando são tratados, constroem conhecimento de forma autônoma.

\section{PALAVRAS-CHAVE}

Cultura Digital. Autoria em Rede. Narrativa transmídia. Fanfics. 


\section{ABSTRACT}

The study investigates the possibilities of learning through authorship in the production of fanfics. The research aims to investigate how subjects immersed in digital culture, through network authorship, from the point of view of transmedia marked in fanfics, learn from productions and collaborations. The methodology includes a qualitative approach, bibliographic and netnographic research. Data were collected from records made through participant observation and analysis of questionnaires applied to research participants, beta readers from the Spirit Fanfics and Histories website. Thus, it was clarified that through freedom, authorship and co-authorship in the network and collaboration, the subjects engage in the production of fictional narratives. And, since they need to appropriate specific contents that are treated in the stories, when they are treated, they build knowledge in an autonomous way.

\section{KEYWORDS}

Digital culture; Network authorship; Transmedia narrative; Fanfics.

\section{RESUMEN}

El estudio investiga las posibilidades de aprender a través de la autoría en la producción de ficciones de fans (fanfics). La investigación tiene como objetivo investigar cómo los sujetos inmersos en la cultura digital, a través de la autoría de la red, desde el punto de vista de transmedia marcado en ficciones de fans, aprenden de producciones y colaboraciones. La metodología incluye un enfoque cualitativo, investigación bibliográfica y netnográfica. Los datos se recopilaron de los registros realizados a través de la observación participante y el análisis de cuestionarios aplicados a los participantes de la investigación, lectores beta del sitio web Spirit Fanfics e Histórias. Por lo tanto, se aclaró que, a través de la libertad, de la autoría y la coautoría en red y de la colaboración, los sujetos participan en la producción de narraciones ficticias. Y, dado que necesitan apropiarse de contenidos específicos que se tratan en las historias, cuando se tratan, crean conocimiento de forma autónoma.

\section{PALABRAS CLAVE}

Cultura digital; Autoría en red; Narrativa transmedia; Ficciones de fans. 


\section{INTRODUÇ̧̃̃o}

A cultura digital e as implicações que essa proporciona são discutidas no presente artigo, no qual ressaltamos a fanfic enquanto narrativa transmídia (NT). Defendemos que a inserção de elementos da transmidiação na constituição da NT, como a autoria em rede, a colaboração na produção de conteúdos e o engajamento com o conteúdo consumido e produzido, marcados nas fanfics, concretizam a aprendizagem por parte dos sujeitos imersos nessa realidade.

Na problemática da pesquisa que originou este artigo, temos: Quais as potencialidades da transmidiação de conteúdos por meio da produção de fanfics para a aprendizagem? O objetivo trabalhado foi investigar como os sujeitos imersos na cultura digital, por meio da autoria em rede, do ponto de vista da transmidiação marcada nas fanfics, aprendem a partir das produções e colaborações. Para isso, investigamos o site Spirit Fanfics e Histórias (https://www.spiritfanfiction.com/home/), lócus da pesquisa.

A metodologia utilizada contemplou a abordagem qualitativa, por meio de pesquisa bibliográfica, no intuito de discutir conceitos relacionados à temática. Para a descrição do site Spirit Fanfics e Histórias foi utilizada a pesquisa netnográfica e a técnica da observação participante. Os dados foram coletados a partir dos registros escritos feitos por meio da observação on-line e da análise dos questionários aplicados a quatro membros do site, os quais possuem a função de beta readers. Para a análise dos questionários foi utilizada a técnica análise de conteúdo, de acordo com Bardin (2011).

A relevância do estudo para a área da Educação, em seus diferentes contextos, bem como para o cenário social, histórico e cultual, está na necessidade de acompanhar o ritmo do contexto atual de interação e colaboração entre os sujeitos imersos na cultura digital, principalmente para os sujeitos que estão inseridos em instituições de ensino e aprendizagem.

Na próxima seção descrevemos a realização da revisão da literatura, apresentamos a fundamentação teórica dos principais conceitos discutidos. Em seguida, apresentamos os procedimentos metodológicos utilizados no desenvolvimento da pesquisa. Na terceira seção, demonstramos parcialmente os resultados alcançados por meio das pesquisas e técnicas de coletada de dados utilizadas. Por fim, apresentamos nossas considerações em relação à temática abordada em relação aos resultados discutidos.

\section{QUADRO TEÓRICO}

\subsection{CULTURA DIGTTAL E AUTORIA EM REDE}

Para iniciar a discussão acerca da cultura digital e da autoria em meio a essa, realizamos um levantamento de estudos embasados nessas temáticas, publicados nos últimos dez anos. As plataformas utilizadas para a coleta desses estudos foram o Scielo, o Portal Educ@ e o Portal de Periódicos da Capes. Utilizamos, na busca destinada à cultura digital, os descritores: cultura digital; cultura digital e educação; cultura e educação; cultura e ensino; cultura e identidade cultural; cultura escrita; 
cultura midiática; cultura participativa; cultura tecnológica; cultura y educación; cultura e linguagem; cibercultura; cultura digital y la educación; cyberculture.

$\mathrm{Na}$ busca destinada à autoria em rede utilizamos os descritores: autoria; autoria colaborativa; autoria coletiva; autoria e colaboração composicional; autorias; autoria múltipla; autoria e tecnologias; autoria e mídias; produser; leitor e autor; lautor; network authorship; authorship; autoria e discursividade; autoria e educação; autoria y educación; autoria e linguagens; autoria colaborativa; autoria em rede; autoria e colaboração.

A partir desse levantamento e de nossas reflexões, afirmamos que a cultura digital, acarretada pelo desenvolvimento das Tecnologias Digitais de Informação e Comunicação (TDIC), proporciona diferentes possibilidades para a educação. Com as características da cultura digital, pensamos nas implicações e possibilidades que esta apresenta para o contexto da aprendizagem, seja ela formal ou informal.

Para pensar nisso, levamos em consideração os estudos de Zuin (2014), Area e Pessoa (2012), Regis e outros autores (2012), Xiberras (2010) e Garcia e Sousa (2011), por meio dos quais verificamos a consonância nas discussões acerca da relação entre a cultura digital e a educação, bem como quais as influências que a realidade das mídias digitais trazem para o ensino e a aprendizagem.

Nas reflexões de Zuin (2014) e Garcia e Sousa (2011) são apresentadas as transformações ocorridas na relação entre professor e aluno a partir do contexto da cultura digital. Essas mudanças acontecem, principalmente, nas metodologias de ensino e aprendizagem utilizadas no processo. No contexto dessa cultura é fundamental que o professor mude sua postura de meros "transmissores de conteúdos" para "orientadores para a aprendizagem", de maneira que engaje o aluno no conteúdo a partir de possibilidades e características apresentadas na cultura digital, sendo estas já vivenciadas pelos sujeitos imersos nessa realidade.

Garcia e Sousa (2011) apresentam um breve histórico do desenvolvimento das tecnologias no meio social. Os autores afirmam que os sujeitos sempre fizeram uso de tecnologias nos processos de comunicação. A princípio, eram utilizadas tecnologias consideradas analógicas, alguns exemplos dessas são: a máquina de datilografia, o livro, o vídeo e a fita cassete, o mimeógrafo, entre outros. Com as transformações culturais e surgimento de algumas necessidades com as TDIC, que estão em constante desenvolvimento a fim de atender, cada vez mais, as necessidades de os sujeitos comunicarem-se, dentre essas: câmera fotográfica digital, jogo digital, celular, computador em suas diferentes versões.

Nos estudos de Area e Pessoa (2012) e Regis e outros autores (2012), são apresentadas propostas de inserção das TDIC na educação e estudos das TDIC no contexto cognitivo, a fim de auxiliar o uso de novas metodologias de ensino e estudos da cibercultura. É de fundamental importância avançar em estudos e práticas acerca da inserção das TDIC nas metodologias do processo de ensino e aprendizagem, uma vez que o contexto em que os sujeitos estão incluídos socialmente, de forma engajada, deve estar inserido nas instituições de ensino formal.

A partir desse contexto, a colaboração na produção de conteúdo é discutida por Xiberras (2010). Para isso, o autor utiliza o conceito das inteligências coletivas e discute como essas acontecem na cibercultura. Para tanto, apresenta e reflete sobre como acontece a construção de conteúdo em diferentes plataformas, como o Facebook e a Wikipédia. 0 autor enfatiza que, por meio da colaboração, 
os sujeitos imersos na cultura digital podem compartilhar, consumir e, principalmente, construir conteúdos em parceria com outros sujeitos.

Backes e Pavan (2014) apresentam resultados de uma pesquisa sobre a interferência da cultura digital em relação aos alunos. Feita com 20 professores, a pesquisa apresenta como o contexto dessa cultura interfere na identidade dos sujeitos e são apresentados pontos que têm relação com a forma de os alunos relacionarem-se e aprenderem. Na conclusão, os autores demonstram que as identidades dos sujeitos, a partir da cultura digital, são ressignificadas constantemente devido ao fluxo constante de conteúdos produzidos e consumidos pelos sujeitos imersos nessa realidade, o que deve ser levado em consideração pelos professores.

Buckingham (2010) e Buzato (2010) discutem sobre a inclusão digital no contexto da educação formal. 0 primeiro discute a necessidade de a escola aceitar e apresentar crítica à cultura digital, como oportunidades de participação dessa no contexto educacional formal. Enquanto Buzato (2010) apresenta vantagens na inclusão digital e inovações tecnológicas na perspectiva de novos letramentos.

Refletir sobre as mudanças culturais na sociedade é necessário para todos os cidadãos, bem como para todas as instituições, principalmente as de ensino. Se a cultura digital envolve e engaja os sujeitos no desenvolvimento de diversas atividades diárias e apresenta possibilidades de aprendizagem, as instituições de ensino poderiam fazer reflexões sobre isso, a fim de, também, engajar os sujeitos no processo de aprendizagem. Dessa forma, acreditamos haver potencialidade para a aprendizagem por meio da inserção da cultura digital no contexto dessas instituições, pois esta cultura já domina o contexto social.

A discussão feita por Buzato (2010) complementa o que discutimos até aqui, de forma mais específica. $\mathrm{O}$ autor trata das possibilidades apresentadas pelas TDIC em novos letramentos. Um sujeito letrado em uma sociedade é aquele capaz de ler e produzir gêneros textuais que circulam no seu espaço social, ou seja, em uma sociedade da cultura digital é necessário que os sujeitos sejam capazes de ler e produzir, de forma efetiva, textos que circulam em todos os espaços dessa sociedade.

A partir disso, destacamos autores que refletem sobre a prática de leitura e de escrita dentro do contexto da cultural digital, uma vez que os sujeitos imersos nesta realidade estão a todo tempo lendo e produzindo textos escritos, seja para qual finalidade for. Isso nos leva a discutir acerca das vantagens trazidas pela cultura digital para a prática da leitura e da escrita por parte dos sujeitos imersos nessa (KLEIMAN, 2014; GLÓRIA; FRADE, 2015).

Nessa perspectiva, Kleiman (2014) apresenta questionamentos sobre o que é ser letrado na contemporaneidade, discutindo práticas de letramento digital e a formação do professor que atua no contexto atual, como agente de letramento no mundo contemporâneo. Glória e Frade (2015) apresentam uma pesquisa prática, na qual foram inseridos computadores em atividades de alfabetização de crianças de 6 anos. Por meio desta pesquisa foi possível verificar as implicações e as possibilidades trazidas pelas mídias digitais para a alfabetização das crianças. Com isso, as autoras concluíram que a inserção do computador nas atividades foi benéfica ao processo de alfabetização das crianças, uma vez que essas tiveram contato com diferentes gêneros textuais, digitais e não digitais, o que foi apresentado como positivo para o processo de aprendizagem de gêneros que circulam no contexto sociocultural. 
Garcia e Sousa (2011) apresentam uma discussão sobre a crise proporcionada pela Segunda Guerra Mundial, a partir da qual foram apoiadas pesquisas para o desenvolvimento da interatividade entre o homem e o computador. Dessa maneira, foram desenvolvidos softwares a fim de atender essa necessidade. Com isso, os sujeitos tiveram ampliação do uso do computador, proporcionando o surgimento da internet. A partir daí essa passou por desenvolvimentos e, hoje, proporciona, de acordo com Garcia e Sousa (2011), cada vez mais possibilidades de acessos a diversos conteúdos, o que faz com que mais conteúdos sejam produzidos, ou seja, um ciclo contínuo que requer dos sujeitos, também cada vez mais, conhecimentos.

Sobre autoria, Arán (2014) discute a imagem do autor a partir de sua consciência e existência, o qual constrói diferentes conhecimentos de si e do mundo por meio da intersubjetividade. Além desse, Menezes (2013) e Santa (2013) discutem acerca da relação das mídias e do ciberespaço na construção de conteúdos por parte das audiências na rede, destacando as características de leitor e autor que se tornam presentes no mesmo sujeito, dando espaço para a coautoria nos ambientes digitais.

Em um contexto mais prático de autoria em rede, Zart e Fraga (2013) e Bassani e Fritz (2013) apresentam discussões acerca da autoria na produção colaborativa de conteúdos na rede. Produção que implica potencialidades, segundo as autoras, para a aprendizagem colaborativa se considerada pela escola para práticas de aprendizagem. Nesta mesma perspectiva, Santos e outros autores (2015) apresentam resultado de uma pesquisa prática aplicada com professores em formação, na qual os sujeitos pesquisados desenvolveram atividades de produção de Recursos Educacionais Abertos (REA). Como resultado, os autores elucidam a contribuição da atividade para a formação de sujeitos-autores e construtores de suas próprias ferramentas pedagógicas.

Veloso et al (2016) e Souza et al (2011), reafirmando as discussões anteriores, defendem que o ciberespaço cada vez mais proporciona o desenvolvimento da autoria em rede, inclusive para o contexto da educação formal. Destacam ainda que esse desenvolvimento e essas possibilidades de autoria em rede devem ser aproveitados tanto pelos alunos como pelos professores, a fim de enriquecer os processos de ensino e de aprendizagem.

Com isso, tratamos do conceito de autoria e como a ascensão da cultura digital implicou e continua implicando nesse conceito. Com o uso de TDIC e da internet os sujeitos podem ser autores e/ou coautores de conteúdos de forma instantânea e contínua. É justamente nessa perspectiva que construímos este capítulo, o desenvolvimento da autoria com o advento da cultura digital.

Além disso, discutimos sobre as implicações da cultural digital no processo de aprendizagem dos sujeitos, de maneira a enfatizar a autoria em rede nesse processo. Uma vez que é apresentada como característica do contexto da cultura atual, está presente na realidade de todos os sujeitos usuários da rede e proporciona a aprendizagem desses, independentemente do tipo de conteúdo consumido e produzido.

\subsection{NARRATIVA TRANSMÍDIA E FANFIC}

Trataremos dos conceitos de NT e fanfic, nos quais evidenciamos suas relações com o contexto da cultura digital e a educação. No intuito de explorar esses conceitos, foi feita uma pesquisa na base de dados do Scielo, portal Educ@ e portal de periódicos da Capes, a fim de verificar o que está sendo 
estudado pelos pesquisadores da área. Nesta pesquisa foram selecionados estudos dos últimos dez anos feitos na área de transmídia e fanfics. Os descritores utilizados na busca destinada à narrativa transmídia foram os seguintes: transmedia storytelling and fanfiction, transmedia storytelling, la narrativa transmedia, narrativa transmídia, transmídia e transmidiação.

A partir do conceito de NT, destacamos as fanfics como exemplo de um fenômeno cultural. Ressaltamos que as fanfics não surgem com o conceito de NT, apenas ganham espaço por meio das possibilidades que surgem com a cultura digital. Na pesquisa feita nas bases de dados citadas e para encontrar textos relacionados às fanfics, utilizamos os seguintes descritores: fanfiction; fansite; fandom; fanpage; fans; fan fictions; fanfics; fanfictions; fanfiction e educação; comunidade de fãs; comunidade de fanfics.

A NT caracteriza-se pela presença de um universo narrativo em diferentes mídias e, além disso, a narrativa presente em cada mídia pode ser consumida de forma individualizada, pois sua construção deve apresentar características do universo narrativo, mas ter uma história que pode ser entendida se consumida individualmente. Ou seja, a partir de uma narrativa presente em um game é possível conhecer o universo do qual esse foi derivado.

Por meio do levantamento feito, destacamos o que apresenta Gosciola (2013) acerca da transmídia. Em seu estudo, o autor conceitua, discute e faz reflexões acerca de conceitos e características da NT. Em meio aos textos selecionados, percebemos uma predominância de discussões feitas sobre a relação entre NT e entretenimento. Sobre essa relação destacamos os estudos de Morelli (2013), Guerrero-Pico (2015), Guerrero (2014), Bona e Sousa (2013).

Outros estudos que utilizam como base a discussão da NT são os de Tavares e Mascarenhas (2013), Renó e outros autores (2011), Renó (2013), que refletem acerca da relação entre transmídia e jornalismo. Na área do Direito encontramos um texto que apresenta discussões sobre a NT, de autoria de Díaz-Noci e Tous-Rovirosa (2012). Por fim, o trabalho de Dioses e outros autores (2017) apresenta, por meio de uma análise da prática, estratégias de comunicação empresarial utilizadas por um grupo editorial que faz uso da transmídia para isso.

Em seu estudo, Morelli (2013) faz uma análise da série Dexter, para isso a autora elucida uma reflexão acerca da situação narrativa e midiática atual. Na discussão, ela destaca que contar uma história por meio da transmídia influencia no sentido final dessa. Além disso, a série Dexter é apresentada como um universo narrativo que faz uso de estratégias da transmídia e é por meio desta análise que a autora apresenta a situação da cultura atual.

Em outro artigo, a transmídia é discutida a partir da série televisiva Fringe, por meio da análise feita pelo autor chega-se à conclusão de que a fanfic, como elemento da NT, apresenta vantagens enquanto ferramenta para a alfabetização midiática. Guerrero-Pico (2015) faz uma análise dos efeitos da NT na criação e consumo de conteúdos de fãs de uma comunidade on-line de fãs da série Fringe.

O autor descreve as características das fanfics no contexto transmidiático, bem como as competências interpretativas e midiáticas desenvolvidas pelos fãs na produção dessas histórias. Guerrero-Pico (2015) parte de uma discussão voltada para o entretenimento, por meio da análise de ações de fãs de uma comunidade on-line dedicada a uma série televisiva e conclui que as fanfics, como 
conteúdos produzidos por fãs nessa comunidade, possui valor como ferramenta para a alfabetização midiática. Logo, percebemos que o autor, apesar de iniciar sua discussão voltada para a relação NT e entretenimento, em sua conclusão apresenta uma possibilidade de valor entre a produção de fanfics, elemento presente em NT e a alfabetização midiática, o que podemos relacionar com a educação.

Guerrero (2014) apresenta diferentes questionamentos acerca da complexidade da NT e dos conteúdos produzidos por fãs de narrativas consideradas transmidiáticas. 0 autor analisa duas séries televisivas por meio de suas características transmidiáticas. Como resultado de pesquisa, Guerrero (2014) apresenta novos papéis desempenhados pelos usuários/fãs de séries televisivas no contexto da cultura digital, no qual apresenta-se a NT. Sujeitos que antes eram apenas consumidores, ou seja, apenas assistiam ao conteúdo das séries televisivas, agora têm a possibilidade de serem consumidores e produtores de conteúdos de forma simultânea.

A partir do conceito de NT apresentado por Jenkins (2009), Bona e Sousa (2013) analisam a universo de The Walking Dead enquanto narrativa transmídia. Os autores apresentam o trajeto feito pela narrativa, que iniciou na história em quadrinhos (HQ) e foi expandida para a série televisiva, websérie e games. Como resultado da análise, os autores afirmam que cada narrativa de The Walking Dead, presente em diferentes mídias, expandem e compõem esse universo narrativo. Dentre os artigos encontrados no levantamento feito, dos que estão relacionados ao entretenimento, apenas um menciona o potencial da NT para a educação. De forma mais específica, o autor afirma que a produção de fanfics pode ser uma ferramenta valiosa para a alfabetização midiática.

Outra área na qual pesquisadores da NT estão dando destaque é o jornalismo transmidiático. Renó e outros autores (2011) discutem o contexto cultural no qual as transformações nas formas de os sujeitos comunicarem-se são destaque e chegam ao conceito de NT como linguagem social na ficção e no jornalismo. Por meio de discussões teóricas e práticas, Renó (2013) apresenta como pode ser elaborado um documentário transmídia e destaca quais padrões de interface esse deve oferecer. Para isso, o autor fundamenta o conceito de NT e discute acerca de características de um documentário transmídia.

Outros que discutem a NT na perspectiva do jornalismo são Tavares e Mascarenhas (2013), estes apresentam as possibilidades trazidas pelo contexto da cultura digital em relação aos sujeitos imersos nela. É dado destaque para a possibilidade de os sujeitos produzirem conteúdos de forma livre, enfatizando os conteúdos jornalísticos que os usuários de mídias digitais produzem de forma contínua.

Nessa discussão, apresenta-se o papel do jornalista e dos novos contadores de histórias que surgiram com as TDIC, além dos novos formatos narrativos. Por fim, os autores deixam como reflexão a interferência que a NT pode apresentar nas regras do jornalismo. A NT em meio a cultura digital proporciona ao sujeito, imerso nessa realidade, possibilidades que o tornam leitor e autor / consumidor e produtor ao mesmo tempo. Com isso, o jornalismo não pertence mais apenas aos jornalistas "formados”, mas também a todos os sujeitos imersos na rede que conheçam conteúdos de cunho jornalístico e queiram compartilhá-los na rede.

A partir dessas possibilidades de produção de conteúdo, a área do Direito também se faz presente no tema da NT. Sobre isso, Díaz-Noci e Tous-Rovirosa (2012) apresentam essas características de produção de conteúdo no contexto da cultura digital, as quais abordam a autoria/(co)autoria. Por meio disso, os autores apresentam reflexões jurídicas sobre esses novos modos de produção de conteúdo. 
Sobre transmídia e comunicação, Dioses e outros autores (2017) apresentam uma pesquisa feita a partir da gestão de conteúdo feito por um grupo editorial do Peru. Para isso, os autores passam pela discussão sobre o surgimento de diversos meios de comunicação, até chegar à difusão de conteúdos por diferentes canais midiáticos e, consequentemente, na NT. Com a fundamentação feita, os autores analisam como um grupo editorial coordena seus conteúdos em diferentes mídias e verificam que o modelo de comunicação utilizado pela empresa pesquisada é um modelo transmídia.

A partir dos estudos analisados, percebemos que apenas um faz relação, de forma direta, com a educação. 0 que nos deixa ainda mais inquietos acerca das possibilidades de aprendizagem proporcionadas pela NT, mais especificamente pela produção de fanfics, que podem ser utilizadas como estratégia no contexto educacional.

As fanfics, produções narrativas de fãs de determinado universo narrativo, não são produzidas por interesses lucrativos, mas sim por afinidade/sentimentos/gosto de sujeitos por determinado filme, história, game, banda, série, desenho animado, romance, artista, personagem. Produzir fanfic é ler e escrever por afeição a determinado universo narrativo.

Por meio da revisão da literatura sobre fanfics, encontramos os textos de Amaral e outros autores (2015); Costa e Reategui (2012); García (2011); Viter (2014); Porto e outros autores (2016); Aguiar (2011). Nestes estudos a leitura e produção de fanfics é relacionado à educação, seja ela formal ou informal.

0 ativismo de fãs, enaltecido pelas possibilidades da cultura digital, é discutido por Amaral e outros autores (2015), as quais apresentam discussões teóricas e práticas sobre o que e como fãs agem a fim de buscar intimidade com o objeto idolatrado, seja filme, personagem, cantor, série, música, romance, novela, ator, entre outros. Viter (2014) também analisou práticas e percepções de um grupo digital, no qual sujeitos leem e produzem textos colaborativos, derivados do romance Orgulho e Preconceito. Para isso, foram discutidos teoricamente os conceitos de comunidade digital e comunidade de prática.

Por meio dessas pesquisas, foram identificados processos de ressignificação das participações dos sujeitos imersos nessa realidade e afirmado que estes sujeitos constroem conhecimento por meio das interações e atividades desenvolvidas. Esses dois textos partem de práticas utilizadas pelos sujeitos para o entretenimento e os autores mencionam possíveis aprendizagens que podem ocorrer por meio dessas práticas.

Costa e Reategui (2012) apresentam uma proposta de aprendizagem de língua inglesa por meio da produção de fanfics. A ideia trabalhada pelos autores foi de os alunos partirem da mineração textual, extração de termos recorrentes em um texto. Com estes termos os alunos foram orientados a criar uma fanfic na língua inglesa e compartilhá-la no meio digital. A partir dos resultados alcançados, foi observado que a técnica de mineração textual deu suporte à produção da fanfic, além de contribuir na aprendizagem da língua inglesa e do letramento digital.

García (2011) destaca a prática de leitura no contexto da cultura digital. O texto apresenta uma discussão comparativa entre a cultura letrada e a cultura digital. Na cultura letrada, a leitura era vista como uma prática superior, por isso poucos tinham acesso. Com a cultura digital, a leitura torna-se uma prática popular. Para o autor, a cultura digital possibilita que o sujeito se aproprie do conteúdo lido. Em meio a essa discussão, reflete-se sobre as implicações culturais e educativas dessa mudança cultural, destacando as fanfics como gênero textual digital. 
0 autor defende que as instituições de ensino devem alfabetizar seus alunos para serem sujeitos sociais ativos. Porém, ele destaca, ainda, que a alfabetização dos sujeitos deve ser integral, ou seja, digital e não digital. Porto e outros autores (2016) apresentam a produção de fanfics como proposta de prática de leitura e escrita na educação formal. As autoras defendem que a produção de fanfics apresenta potências para o desenvolvimento das habilidades de leitura e escrita. Para isso, discutem acerca da convergência midiática e as mudanças que esta trouxe para a produção e disseminação de conteúdo. A partir dessa discussão são enaltecidas a leitura e produção de textos nesse contexto, destacando o gênero fanfic.

No estudo feito por Aguiar (2011) são apresentadas propostas metodológicas para o ensino de língua e literatura por meio de narrativas contemporâneas. A autora discute sobre narrativas contemporâneas, citando a fanfic. Além disso, é feita uma descrição de como acontece o processo de leitura e escrita nos veículos midiáticos. São apresentados modelos de ensino de língua e literatura a partir dessas novas narrativas. Segundo a autora, o ensino desses novos modelos de comunicação tem como objetivo tornar o aluno um sujeito com voz e vez na sociedade contemporânea. Com os estudos apresentados, foi possível perceber que as fanfics estão sendo estudadas, inclusive como potência para a educação.

\section{PROCEDIMENTOS METODOLÓGICOS}

A pesquisa investiga acerca de como ocorre aprendizagem em espaços de produção de fanfics. Utilizamos a abordagem da pesquisa qualitativa, por meio de pesquisa exploratória do tipo bibliográfica e netnográfica. Nessa etapa foi feita uma observação participante no site Spirit Fanfics e Histórias (https://www.spiritfanfiction.com/home/), a partir de um roteiro a fim de estruturá-la, que serviu de guia para o registro escrito e descrição do que foi observado.

Realizamos uma pesquisa bibliográfica, na qual foram fundamentados os conceitos de cultura digital, autoria em rede, NT, transmidiação e fanfics, principalmente. Para o estudo do site Spirit Fanfics e Histórias utilizamos a pesquisa netnográfica. Por meio dessa, observamos a plataforma na qual as histórias são produzidas e disponibilizadas, por sujeitos fãs de determinado universo transmídia ou de livro, filme, música, banda musical, novela, personagem (real ou fictício). Coletamos dados descritivos acerca do site a partir da observação e de registros escritos guiados pelo roteiro de observação criado para isso.

Também por meio da observação participante, entramos em contato com alguns autores de fanfics a fim de solicitar o envio de fics que passaram pela revisão de algum beta reader. As histórias selecionadas para esse contato foram as que estavam em destaque do dia 19 de dezembro de 2018 a 30 de janeiro de 2019.

Os usuários do site selecionados foram os beta readers da comunidade, escolhidos pelo fato de serem tanto leitores e produtores de fanfics, como colaboradores das produções dos outros usuários do site. Sendo assim, utilizamos, também para a coleta de dados, o questionário on-line aplicado aos beta readers do Spirit Fanfics e Histórias. 
Os beta readers são usuários selecionados pelos administradores do site para ficarem a disposição dos outros no caso de esses precisarem de revisões textuais e orientações na/sobre suas produções. Para a análise, utilizamos a técnica da análise de conteúdo. De acordo com os procedimentos de análise de conteúdo apresentados por Bardin (2011), após a leitura, organização e codificação dos conteúdos dos questionários respondidos, elencamos as categorias de análise deste estudo: (1) liberdade do sujeito em produzir a partir da sua subjetividade; (2) autoria e coautoria em rede na perspectiva dos beta readers do Spirit Fanfics e Histórias; (3) colaboração que há na produção das fanfics; (4) engajamento do sujeito com a diversidade de conteúdos possíveis de serem abordados nas fanfics.

\section{DISCUSSÃO DOS RESULTADOS}

A partir dos procedimentos de análise de conteúdo (BARDIN, 2011), elencamos as categorias de análise a partir dos conteúdos coletados nos questionários dos beta readers. Os resultados abrangem reflexões acerca da autoria e coautoria em rede, com a utilização dos elementos da transmidiação marcados nas fanfics, como a liberdade, a colaboração, o engajamento em leituras e produções de conteúdo, valendo-se destes elementos para o processo de aprendizagem. Apresentaremos a análise dos questionários on-line a partir das categorias elencadas na primeira etapa da análise de conteúdo.

Nas respostas dadas aos questionários, a escrita livre proporciona ao autor do texto apresentar-se por meio da produção, ou seja, é possível reconhecer algumas características desse por meio da leitura de seus escritos. Nesse contexto, a subjetividade do autor está presente em cada uma de suas produções e a liberdade da escrita contribui para este propósito. Com isso, afirmamos que a liberdade em produzir o que almeja, apresentando sua subjetividade, estimula ao sujeito produzir suas histórias.

A autoria em rede, no contexto da leitura e da produção de fanfics, contribui para a aprendizagem do sujeito, tanto autor como leitor. Isso acontece pelo fato de haver interação entre eles com a finalidade de aprimorar o conteúdo. Interação esta proporcionada, no caso das comunidades de fanfics, pela troca de conhecimentos, informações por meio de críticas, comentários, opiniões.

A colaboração instiga os sujeitos em suas produções (isso vai depender do sujeito e de suas preferências), além de contribuir para o aprimoramento da escrita desses (menor propensão a erros gramaticais, dentre outros problemas de escrita). Enfim, com a qualidade dos textos publicados, no caso as fanfics.

Elucidamos que, por meio da liberdade, autoria em rede e colaboração, os sujeitos são instigados a produzir narrativas ficcionais. Por sentirem-se instigados, os sujeitos engajam-se na produção e, uma vez que precisam apropriar-se de conteúdo específicos, quando tratados nas histórias, desenvolvem aprendizagem de forma autônoma, por meio de buscas de informações e, consequentemente, construção de conhecimento. 


\section{CONSIDERAÇÕES FINAIS}

A comunicação dos sujeitos que vivem em sociedade adequa-se à cultura de cada contexto e, com o surgimento e desenvolvimento das TDIC, essa ação ganha outras características. Diante disso, o comportamento dos sujeitos imersos nessa realidade acompanha essas mudanças em relação às formas de comunicação e expressão.

A partir disso, propomo-nos a discutir conceitos relacionados a esse contexto. E, ainda, estudar e analisar um site que tem como finalidade a publicação de narrativas ficcionais. A pesquisa em desenvolvimento, a partir dos resultados já alcançados, permite-nos tecer algumas considerações acerca da temática abordada. Dentre elas, identificamos, por meio dos resultados alcançados, potencialidades na prática de produção de fanfics para a aprendizagem.

A liberdade, do modo como pensamos, estimula o sujeito que possui criatividade, principalmente, a produzir sem precisar atender padrões pré-estabelecidos. Sobre a (co)autoria, percebemos que os sujeitos não se sentem (co)autores dos universos os quais são desdobrados por suas fanfics, assim, nossa reflexão sobre a vaidade proporcionada pela (co)autoria dos universos foi refutada.

A aprendizagem na prática de produção de fanfics leva em consideração elementos como a liberdade, a autoria e a colaboração, ficando evidenciado que esses instigam os sujeitos a produzirem. Uma vez instigado por esse conjunto de elementos, esses engajam-se nas produções de modo que sentem necessidade de levar qualidade aos seus textos. Levando em consideração que há a possibilidade de envolver diversos conteúdos na produção de narrativas ficcionais, a depender do nível de conhecimento e da necessidade do ficwriter, este vai buscar conhecimento a fim de apresentar a qualidade pretendida aos seus leitores.

Os resultados deste estudo podem ser levados em consideração por profissionais da educação, a fim de refletirem acerca da inserção, em suas práticas de ensino, das TDIC e suas implicações no contexto sociocultural. Podemos considerar este estudo como uma diretriz que pode ser pensada e adequada a diferentes componentes curriculares, de modo que serem trabalhados o desenvolvimento da aprendizagem do sujeito, da autonomia desse, bem como proporcionará a ampliação da percepção acerca dos gêneros textuais que circulam no contexto da cultura digital.

\section{REFERÊNCIAS}

AGUIAR, Jacqueline G. Fanfictions e RPG's: narrativas contemporâneas. Àgora, Porto Alegre, ano 2, p. 25-35, jul./dez. 2011.

AMARAL, Adriana; SOUZA, Rosana V.; MONTEIRO, Camila. “De westeros no \#vemprarua à shippagem do beijo gay na TV brasileira”. Ativismo de fãs: conceitos, resistências e práticas na cultura digital. Galaxia, São Paulo, n. 29, p. 141-154, jun. 2015. 
ARÁN, Pampa O. A questão do autor em Bakhtin. Bakhtiniana, São Paulo, Número Especial, p. 4-25, jan./jul. 2014.

AREA, Manuel; PESSOA, Teresa. De lo sólido a lo líquido: las nuevas alfabetizaciones ante los cambios culturales de la Web 2.0. Comunicar: Revista Científica de Educomunicación, v. XIX, n. 38, p. 13-20, 2012.

BACKES, José L.; PAVAN, Ruth. As identidades dos alunos em tempos de cultura digital: a percepção dos professores de educação básica. Revista da FAEEBA - Educação e Contemporaneidade, Salvador, v. 23, n. 42, p. 219-227, jul./dez. 2014.

BARDIN, Laurence. Análise de conteúdo. São Paulo: Edições 70, 2011.

BASSANI, Patrícia B.; FRITZ, Rosi S. Aprendizagem em/na rede: comunidades virtuais de aprendizagem em blogs. Revista Diálogo Educacional, Curitiba, v. 13, n. 40, p. 895-912, set./dez. 2013.

BONA, Rafael J.; SOUSA, Marina P. As histórias em quadrinhos e suas extensões em produtos midiáticos: a narrativa transmidiática de The Walking Dead. Sessão do imaginário, Porto Alegre, v. 18, n. 30, p. 57-67, 2013.

BUCKINGHAM, David. Cultura digital, educação midiática e o lugar da escolarização. Educação \& Realidade, Porto Alegre, v. 35, n. 3, p. 37-58, set./dez. 2010.

BUZATO, Marcelo K. Cultura digital e apropriação ascendente: apontamentos para uma educação 2.0. Educação em Revista, Belo Horizonte, v. 26, n. 3, p. 283-304, dez. 2010.

COSTA, Patrícia S.; REATEGUI, Eliseo B. Oportunidades de letramento através de mineração textual e produção de Fanfictions. RBLA, Belo Horizonte, v. 12, n. 4, p. 835-859, 2012.

DÍAZ-NOCI, Javier; TOUS-ROVIROSA, Anna. La audiencia como autor: narrativas transmedia y propiedad intelectual del público - Algunas reflexiones jurídicas. El profesional de la información, Barcelona, v. 21, n. 5, p. 458-467, set./out. 2012.

DIOSES, Kelly R.; ROJAS, Tomás A.; MORENO, Henry P. De la comunicación multimídia a la comunicación transmedia: uma revisión teórica sobre las actuales narrativas periodísticas. Estudios sobre el mensaje periodístico, Madrid, v. 23, n. 1, p. 223-240, jul. 2017.

GARCÍA, Alberto E. Sobre el concepto de apropiación de Chartier y las nuevas prácticas culturales de lectura (el fan fiction). Álabe, Almeria, n. 4, p. 1-23, dez. 2011. 
GARCIA, J. C. R.; SOUSA, M. R. F. Cultura digital: odisseia da tecnologia e da ciência. Em Questão, Porto Alegre, v. 17, n. 2, p. 77-90, jul./dez. 2011.

GLÓRIA, Julianna S.; FRADE, Isabel. C. A alfabetização e sua relação com o uso do computador: o suporte digital como mais um instrumento de ensino-aprendizagem da escrita. Educação em Revista, Belo Horizonte, v. 31, n. 3, p. 339-358, jul./set. 2015.

GOSCIOLA, Vicente. Transmidiação: formas narrativas em novas mídias. Fonseca Journal of Communication, Salamanca, n. 2, p. 270-284, 2013.

GUERRERO, Mar. Webs televisivas y sus usuarios: un lugar para la narrativa transmedia. Los casos de “Águila Roja” y “Juego de Tronos” en España. Nueva época, Santa Fé, n. 21, p. 239-267, jan./jun. 2014.

GUERRERO-PICO, Mar. Producción y lectura de fan fiction en la comunidad online de la serie Fringe: transmedialidad, competencia y alfabetización mediática. Palabra clave, Chía, v. 18, n. 3, p. 722-745, set. 2015.

JENKINS, Henry. Cultura da convergência. 2. ed. São Paulo: Aleph, 2009.

KLEIMAN, Angela B. Letramento na contemporaneidade. Bakhtiniana, São Paulo, v. 9, n. 2, p. 72-91, ago./dez. 2014.

MENEZES, Leonardo M. A realidade construída pela produção documental participativa. Galáxia, São Paulo, n. 26, p. 227-238, dez. 2013.

MORELLI, María R. Análisis de la serie “Dexter”: una aproximación a su relato en la cultura de la convergência. La trama de la comunicación, Rosario, v. 17, p. 151-161, jan./dez. 2013.

PORTO, Cristiane M.; BENIA, Renata T.; LIMA, Daniella J. ‘Unleash your imagination’: os fandoms e a contribuição das fanfictions para o contexto educacional baseada no caso da narrativa de HIM. Acta Scientiarum Education, Maringá, v. 38, n. 4, p. 373-382, out./dez. 2016.

REGIS, F.; TIMPONI, R.; MAIA, A. Cognição integrada, encadeada e distribuída: breve discussão dos modelos cognitivos na cibercultura. Comunicação, mídia e consumo, São Paulo, ano 9, v. 9, n. 26, p. 115-134, nov. 2012.

RENÓ, Denis. Interfaces e linguagens para o documentário transmídia. Fonseca Journal of Communication, Salamanca, n. 2, p. 204-225, 2013. 
RENÓ, Denis P.; VERSUTI, Andréa C.; GONÇALVES, Elizabeth M.; GOSCIOLA, Vicente. Narrativas transmídia: diversidade social, discursiva e comunicacional. Palabra clave, Chía, v. 14, n. 2, p. 201-215, dez. 2011.

SANTA, Everton V. O jogo autor-leitor na literatura do agora. Estudos de Literatura Brasileira Contemporânea, Brasília, n. 42, p. 209-221, jul./dez. 2013.

SANTOS, Edméa; PONTE, Felipe S.; ROSSINI, Tatiana S. Autoria em rede: uma prática pedagógica emergente. Revista Diálogo Educacional, Curitiba, v. 15, n. 45, p. 515-536, maio/ago. 2015.

SOUZA, Marcia I.; SILVA, Luciana O.; ARAÚJO, Izabel C. Autoria na Web 2.0 no contexto da educação e a ética dos hackers. ETD: Educação Temática Digital, Campinas, v. 12, n. esp., p.154-173, mar. 2011.

TAVARES, Olga; MASCARENHAS, Alan. Jornalismo e convergência: possibilidades transmidiáticas no jornalismo pós-massivo. Revista Famecos, Porto Alegre, v. 20, n. 1, p. 193-210, jan./abr. 2013.

VELOSO, Maristela M.; BONILLA, Maria H.; PRETTO, Nelson L. A cultura da liberdade de criação e o cerceamento tecnológico e normativo: potencialidades para a autoria na educação. ETD: Educação Temática Digital, Campinas, v. 18, n. 1, p. 43-59, jan./abr. 2016.

VITER, Luciana N. Construção de letramento em uma comunidade on-line de práticas de leitura e produção textual. Recorte, Belo Horizonte, v. 11, n. 1, p. 1-18, jan./jun. 2014.

XIBERRAS, Martine. Internautas: inteligências coletivas na cibercultura. Revista Famecos, Porto Alegre, v. 17, n. 3, p. 253-265, set./dez. 2010.

ZART, Lidia H.; FRAGA, Dinorá M. Ferramentas tecnológicas para investigação de autoria. Revista Brasileira de Linguística Aplicada, Belo Horizonte, v. 13, n. 1, p. 67-83, 2013.

ZUIN, Antônio A. A cultura digital, a semiformação e o novo elo pedagógico. Inter-Ação, Goiânia, v. 39, n. 2, p. 241-256, maio/ago., 2014. 
2 Mestre em Educação - UNIT/SE; Doutoranda em Educação - PPGE/CEDU/UFAL; Professora nas Faculdades Integradas do Extremo Sul da Bahia - UNESULBAHIA/UniFTC; Membro do Grupo de Pesquisa Tecnologias da Informação e Comunicação na Formação de Professores Presencial e a Distância on-line - TICFORPROD/UFAL/CNPq.

E-mail: daniellalima90@gmail.com

3 Doutor em Educação - PUC/SP; Professor Titular da Universidade Federal de Alagoas - UFAL; Líder do Grupo de Pesquisa Tecnologias da Informação e Comunicação na Formação de Professores Presencial e a Distância On-line - TICFORPROD/UFAL/CNPq.

E-mail: luispaulomercado@gmail.com 